\title{
Social and self-perceptions of institutionalized and noninstitutionalized juveniles
}

\author{
KEVIN I. MINOR, SHARON K. KARR and STEPHEN F. DAVIS \\ Emporia State University, Emporia, Kansas
}

\begin{abstract}
The present study assessed the social- and self-perceptions of 71 institutionalized delinquents and 210 noninstitutionalized high school students in an attempt to identify possible differences in these perceptions and address the issue of labeling. Subjects were administered a semantic differential instrument containing scales measuring self-perceptions and the social perceptions of six status groups. The data were analyzed utilizing confinement status (institutionalized vs. noninstitutionalized) and gender as control variables. Results revealed no difference between institutionalized and noninstitutionalized groups in self-perceptions; both were relatively positive. The self-perceptions of institutionalized subjects were significantly higher than their perceptions of problem teenagers and criminals. A variety of additional significant effects are also presented. Possible interpretations of the findings, as well as implications for treatment methodology, recidivism rate analyses, and future research are discussed.
\end{abstract}

Investigators (e.g., Jurkovic, 1980; Lueger \& Cadman, 1982) have shown interest in identifying the nature of the cognitive variables associated with juvenile delinquency. Specifically, research has focused on delinquents' perceptions of themselves (self-perception or self-concept) and on their perceptions of particular social status groups (social perception). Self-perception research itself has often been concerned with the question of whether or not application of the label "delinquent" promotes adolescent identification and behavior that is consistent with the label's implications (Becker, 1973).

Jensen (1972) provided support for the possibility that delinquents identify with assigned labels by demonstrating that juveniles who had been officially labeled as delinquent tended to think of themselves as delinquent to a greater extent than those who had not been so labeled. However, negative behavioral evaluations by certain persons in a delinquent's life do not ensure that the delinquent will internalize these evaluations. Several studies (Chassin, Eason, \& Young, 1981; Chassin, Presson, Young, \& Light, 1981; Maher \& Stein, 1968) have in fact shown that institutionalized delinquents do not typically view themselves as delinquents.

Similarly, Jensen (1972) reported finding a negative correlation between self-esteem and delinquency involvement. However, other researchers (e.g., Fiedler \& Bass, 1959) have demonstrated that delinquent subjects tend to display more favorable self-perceptions than control subjects. Regarding this latter finding, some investigators (Eyo, 1981; Lund \& Salary, 1980) have reported that

Portions of this article were presented at the meeting of the Association of Psychological and Educational Research in Kansas, Kansas City, MO, October 1,1983 . The authors gratefully acknowledge the assistance of William Thompson for his comments on this study. Requests for reprints of this article should be sent to Sharon Karr, Psychology Department, Emporia State University, Emporia, KS 66801. delinquent subjects show more defensive attitudes in relation to their self-perceptions than do control subjects. Therefore, it seems tenable that a delinquent could conceal a basic sense of worthlessness by attempting to convey a positive self-perception.

A finding that delinquents display positive selfperceptions could also imply that delinquents possess defensive attitudes about themselves that allow illegal behavior to be attributed to sources other than personal inadequacies. The way a delinquent attributes his/her illegal behavior will impact upon what he/she will do to change the behavior (Quicker, 1973). If blame is attributed to personal inadequacies, as might be reflected in negative self-perceptions, delinquents may well try to modify their own behavior in an attempt to conform more adequately to society's conventional behavioral standards. If, however, blame is attributed to general societal or juvenile justice system inadequacies, as reflected in positive selfperceptions, delinquents may continue to engage in illegal behavior despite intervention.

Moreover, there is evidence that supports the position that delinquent adolescents (Ganger \& Sarason, 1973; Maher \& Stein, 1968) and adult offenders (Chang, 1977; Chang \& Iacovetta, 1981; Chang \& Zastrow, 1976) tend to display unfavorable social perceptions of groups associated with the juvenile and criminal justice systems, respectively. These findings are consistent with the position that delinquents attribute their problems to social, rather than personal, inadequacies. If this is in fact true, then the frequent failure of intervention efforts and the corresponding high rate of delinquency recidivism are hardly surprising.

One purpose of the present study was to address the labeling issue by determining the nature of the relationship between the self-perceptions of a group of institutionalized delinquents and the delinquents' social per- 
ceptions of two status groups: problem teenagers and criminals. Another purpose was to compare both the selfand social perceptions of the institutionalized group with the similar perceptions of a group of noninstitutionalized adolescents to determine whether significant differences were present.

\section{METHOD}

\section{Subjects}

The control subjects were 89 white male and 121 white female student volunteers obtained from the study halls of a public high school. These subjects ranged in age from 14 to 18 years (mean $=15.7$ years). The institutionalized subjects consisted of 30 male and 41 female delinquents ranging in age from 12 to 18 years (mean $=15.9$ years). The institutionalized male subjects were drawn from a private minimumsecurity juvenile institution and were selected by the staff on the basis of Wide Range Achievement Test reading scores of a 6.5 grade level or higher. This group was composed of all whites, except for one black and one American Indian subject. The institutionalized female subjects were volunteers from a state-supported minimum-security juvenile institution. This group was composed of the following: 22 white subjects, 10 black subjects, and 9 subjects from other ethnic groups.

\section{Procedure}

The instrument used for measuring perceptions was a semantic differential scale consisting of 20 pairs of bipoloar adjectives, each of which conveyed essentially opposite meanings (e.g., violent-nonviolent, sincereinsincere). The general semantic differential scale was developed by Osgood, Suci, and Tannenbaum (1957), and the specific scale used in this study had been employed previously by Chang and his colleagues (Chang, 1977; Chang \& Iacovetta, 1981; Chang \& Zastrow, 1976) in their studies of adult inmates' perceptions.

Although the subjects were actually asked to rate a total of 12 status groups (1 group per semantic differential page), 6 of the status groups merely served as filler items and were not intended to be relevant to the specific research issues under consideration. Hence, only ratings of the remaining 6 groups will be considered. These include: police officers, criminals, social workers, problem teenagers, juvenile court judges, and correctional officers. The subjects were asked to rate themselves on the final scale page ("I am"). All ratings were made on a 5-point basis, with lower ratings indicating negative or unfavorable perceptions.

The bipolar adjectives, the status-group categories, and the instructions were subjected to reading-level analyses (Dale \& Chall, 1948a, 1948b; Dale \& O'Rourke, 1979) to ascertain the probability of a person with a low reading level being able to read and understand the assessment instrument. The results of these analyses, along with field test results obtained from 20 fourth- and fifth-graders, demonstrated that the instrument was sufficiently simple to permit reading and understanding by the subjects selected for this study. The questionnaire was group administered to all subjects, with the administrator providing assistance to subjects as needed.

\section{RESULTS}

The sum of the 20 responses for each status group and "I am" scale was computed for each subject. Group means for the seven scales are shown in Table 1.

Seven separate one-way analyses of variance were conducted to determine whether any differences existed among the three ethnic institutionalized female groups in their appraisal of each status-group scale and the "I am" scales. (A significance level of .05 was adopted for the evaluation of all statistical tests.) No significant group effects were obtained. In view of this, the data for all institutionalized females were pooled for all seven scales.
Table 1

Summary of Group Means with Sex of Subjects Controlled

\begin{tabular}{lccccc}
\hline & \multicolumn{2}{c}{ Institutionalized } & & \multicolumn{2}{c}{ Noninstitutionalized } \\
\cline { 2 - 3 } \cline { 5 - 6 } \multicolumn{1}{c}{ Status Groups } & Males & Females & & Males & Females \\
\hline Police Officers & 73.40 & 56.41 & & 75.42 & 80.91 \\
Criminals & 40.50 & 44.85 & & 34.74 & 30.21 \\
Social Workers & 72.93 & 70.78 & & 77.74 & 86.78 \\
Problem Teenagers & 49.50 & 54.93 & & 46.69 & 48.30 \\
Juvenile Court Judges & 67.03 & 63.24 & & 75.22 & 81.42 \\
Correctional Officers & 59.53 & 69.05 & & 71.60 & 79.46 \\
I am & 75.33 & 77.78 & & 83.22 & 87.04 \\
\hline
\end{tabular}

A separate $2 \times 2$ factorial weighted-means analysis of variance was employed to determine what, if any, difference existed between gender and confinement status for each scale. The results of these analyses indicated that the gender factor was significant for the social workers and correctional officers scales; institutionalized and noninstitutionalized females displayed significantly higher perceptions of correctional officers than did institutionalized and noninstitutionalized males, respectively $[F(1,277)$ $=17.59, \mathrm{p}<.001]$. Likewise, the confinement-status factor was significant for the police officers, criminals, social workers, problem teenagers, juvenile court judges, and correctional officers scales; the institutionalized subjects displayed significantly higher perceptions of problem teenagers $[F(1,277)=7.82, p<.01]$ and significantly lower perceptions of correctional officers $[\mathrm{F}(1,277)=$ $24.49, \mathrm{p}<.001]$ than did noninstitutionalized subjects. The gender $\times$ confinement status interaction was found to be significant for the police officers, criminals, social workers, and juvenile court judges status groups. Specific comparisons were made through the use of simple-effects analysis (Keppel, 1982). The results of these analyses are briefly summarized as follows. The evaluation of gender effects at specific levels of confinement status indicated: (1) institutionalized males displayed significantly higher perceptions of police officers $[F(1,277)=24.05, p<$ $.001]$ than did institutionalized females; (2) control males displayed significantly higher perceptions of criminals than did control females $[F(1,277)=6.23, p<.025]$; (3) control females displayed significantly higher perceptions of police officers $[\mathrm{F}(1,277)=7.45, \mathrm{p}<.01]$, social workers $[\mathrm{F}(1,277)=21.18, \mathrm{p}<.001]$, and juvenile court judges $[F(1,277)=6.65, \mathrm{p}<.025]$ than did control males. The comparison of confinement-status effects at specific gender levels indicated: (1) institutionalized males displayed significanly higher perceptions of criminals than did control males $[\mathrm{F}(1,277)=4.41, \mathrm{p}<.05]$; (2) institutionalized females displayed significantly higher perceptions of criminals than did control females $[F(1,277)=38.93, p<.001] ;(3)$ control males displayed significantly higher perceptions of juvenile court judges than did institutionalized males $[\mathrm{F}(1,277)=5.09$, $\mathrm{p}<.05$ ]; (4) control females displayed significantly higher perceptions of police officers $[\mathrm{F}(1,277)=88.40$, $\mathrm{p}<.001]$, social workers $[\mathrm{F}(1,277)=39.65, \mathrm{p}<.001]$, and juvenile court judges $[\mathrm{F}(1,277)=34.19, \mathrm{p}<.001]$ than did institutionalized females. 
Inspection of Table 1 indicates that the self-perceptions of both the institutionalized and the noninstitutionalized subjects were relatively positive. In order to determine the nature of the relationships between the institutionalized subjects' self-perceptions and their perceptions of problem teenagers and criminals, respectively, two separate, independent-groups $t$ tests were performed. The results of these analyses indicated that institutionalized subjects displayed significantly higher perceptions of themselves than of problem teenagers $[\mathrm{t}(140)=10.62$, $\mathrm{p}<.001]$ and criminals $[(\mathrm{t}(140)=11.78, \mathrm{p}<.001]$, respectively.

\section{DISCUSSION}

The present finding that the self-perceptions of institutionalized delinquents were significantly higher than the delinquents' social perceptions of problem teenagers and criminals is consistent with previous research (Chassin, Eason, \& Young, 1981; Chassin, Presson, Young, \& Light, 1981; Maher \& Stein, 1968) proposing that delinquents do not tend to identify with delinquent labels or internalize society's negative behavioral evaluations. However, the drawing of firm conclusions on this point is not warranted by the present data because of a second finding that institutionalized subjects displayed significantly higher perceptions of problem teenagers and criminals than did control subjects. It seems possible that institutionalized delinquents have higher regard for deviant status groups than control subjects do, but that delinquents nonetheless perceive themselves in a favorable, rather than in a deviant, manner. On the other hand, it is plausible that institutionalized subjects' selfperceptions were higher than their social perceptions of problem teenagers and criminals because of the presence of defensive "self' attitudes. If this were the case, the difference between self-perceptions and social perceptions would seem to reflect this defensiveness.

Likewise, both institutionalized and control subjects displayed selfperceptions that were relatively positive and not significantly different from each other. This finding could mean that delinquents do not tend to internalize societal negative evaluations and that most simply have positive self-concepts. Conversely, this finding could be construed as suggesting that delinquents possess defensive "self" attitudes and that obtained positive self-perceptions reflect attempts to cover up a basic sense of worthlessness. However, one could argue that defensiveness, if present, should have been manifested in deliquents displaying significantly higher self-perceptions than controls. Such a finding, had it been obtained, would have provided more convincing evidence for the position that delinquents are overly defensive of themselves.

Recall also that institutionalized subjects tended to display significantly more negative perceptions than did controls of status groups associated with the legal role. This finding is consistent with the results of past studies of adult and juvenile offenders (Chang, 1977; Change \& Iacovetta, 1981; Chang \& Zastrow, 1976; Maher \& Stein, 1968). Taken in conjunction with the findings described above, this result could mean that the defensive self-perceptions of delinquents allow them to attribute problematic behavior to societal and justice system inadequacies, rather than to personal inadequacies. However, it is possible that delinquents simply have negative regard for status groups associated with the legal role and that they possess favorable self-concepts that are relatively devoid of deviant elements. Clearly, future research is needed to clarify these issues.

In summary, the present findings have implications for treatment methodology, recidivism-rate analyses, and future research. The fact that gender differences surfaced in the analysis of social perceptions implies that the gender variable needs to be considered when research is conducted on the perceptions of juvenile delinquents. The finding that institutionalized subjects generally displayed more negative perceptions of groups with legal-role affiliation than did controls implies that personnel throughout the juvenile justice system should be aware of the possible presence of these perceptions. Furthermore, some alteration of these perceptions might be attempted before proceeding with other forms of intevention. Otherwise, various forms of treatment may be re- jected and thus be of minimal value in lessening the probability of recidivism. Finally, before new behaviors can be taught to and internalized by delinquents, they must first be convinced that their previous illegal behaviors were wrong and self-defeating. In short, delinquents must be convinced that their behavior merits change. The findings that institutionalized subjects displayed relatively positive self-perceptions, that there were no significant differences between control and institutionalized subjects in self-perceptions, and that institutionalized subjects displayed higher perceptions of themselves than of problem teenagers and criminals implies that institutionalized delinquents may often fail to view their prior illegal behavior as being wrong and attributable to personal inadequancies. This faulty perception could also contribute to the rejection of treatment and to subsequent recidivism.

\section{REFERENCES}

BECKER, H. S. (1973). Outsiders: Studies in the sociology of deviance. New York: Free Press.

Chang, D. H. (1977). Crime and delinquency. Cambridge, MA: Schenkman.

Chang, D. H., \& IAcovetta, R. G. (1981). Perceptual evaluation as an index for conflict resolution and criminal rehabilitation. Indian Journal of Criminology and Criminalistics, 1, 28-39.

ChANG, D. H., \& ZASTROW, C. H. (1976). Inmates' and security guards' perceptions of themselves and of each other: A comparative study. International Journal of Criminology and Penology, 4, 89-98.

Chassin, L., Eason, B. J., \& Young, R. D. (1981). Identifying with a deviant label: The validation of a methodology. Social Psychology Quarterly, 44, 31-36.

Chassin, L., Presson, C. C., Young, R. D., \& Light, R. (1981). Self-concepts of institutionalized adolescents: A framework for conceptualizing labeling effects. Journal of Abnormal Psychology, 90, 143-150.

Dale, E., \& Chall, J. S. (1948a). A formula for predicting readability. Educational Research Bulletin, 27, 11-20.

Dale, E., \& Chall, J. S. (1948b). A formula for predicting readability: Instruction. Educational Research Bulletin, 27, 37-54.

DALE, E., \& O'ROURKe, J. (1979). The living word vocabulary: The words we know. Elgin, IL: Dome Press.

EYo, I. E. (1981). Relationship between social desirability and selfcriticism in subgroups of male and female delinquents and nondelinquents. Psychological Report, 49, 711-716.

FIEDLER, F. E., \& BASS, A. R. (1959). Delinquency, confinement, and interpersonal perception (Tech. Rep. No. 6; USPH Grant M1774). Urbana, IL: University of Illinois.

GANGER, V. J., \& SARASON, I. G. (1973). Variables associated with recidivism among juvenile delinquents Journal of Consulting and Clinical Psychology, 40, 1-5.

JenSEN, G. F. (1972). Delinquency and adolescent self conceptions. A study of the personal relevance of infraction. Social Problems, 20, 84-101.

JURKOvIC, G. J. (1980). The juvenile delinquent as a moral philosopher: A structural-developmental perspective. Psychological Bulletin, 88, 709-727.

KEPPEL, G. (1982). Design and analysis: A researcher's handbook (2nd ed.). Englewood Cliffs, NJ: Prentice-Hall.

LUEGER, R. J., \& CADMAN, W. (1982). Variables associated with recidivism and program-termination of delinquent adolescents. Journal of Clinical Psychology, 38, 861-863.

LUND, N. L., \& SALARY, H. M. (1980). Measured self-concept in adjudicated juvenile offenders. Adolescence, 15, 65-74.

MAHER, B., \& STEIN, E. (1968). The delinquent's perception of the law and community. In S. Wheeler (Ed.), Controlling delinquents (pp. 187-221). New York: Wiley.

Osgood, C., Suci, G. J., \& Tannenbaum, P. H. (1957). The measurement of meaning. Urbana, IL: University of Illinois Press.

QUICKER, J. C. (1973). A consideration of the relationship of "punitiveness" to delinquency as developed in opportunity theory. Journal of Criminal Law and Criminology, 13, 333-338.

(Revision received for publication July 26, 1984.) 